Lepr Rev (1989) 60, 169-177

\title{
Editorial
}

\section{DISABILITY CONTROL IN A LEPROSY CONTROL PROGRAMME}

\section{Introduction}

The Sixth Report of the WHO Expert Committee on Leprosy ${ }^{1}$ recommends that 'prevention and management of impairments and disabilities, which have long been recognized as essential components of leprosy control programmes, should be implemented effectively'.

It is recognized that the best way to seek to prevent disabilities is to detect and treat patients at a very early stage in the disease. ${ }^{2}$ It must, however, be emphasized that early detection and early treatment are no guarantee that nerve damage will not occur, though they minimize the risk. Sadly many patients still register for treatment with irreversible peripheral nerve dysfunction. The 1987 LEPRA Report ${ }^{3}$ shows that $21.9 \%$ of new Malawian patients had disabilities (WHO disability grades 1 to 3 ) on diagnosis, and this occurred in a programme that delivers treatment to within 3 miles of patients' homes. The 1987 Tanzania National Leprosy and TB Programme Report ${ }^{4}$ shows that $30 \%$ of the new patients had disabilities grades 1 to 3 . Becx-Bleumink ${ }^{5}$ reports that $28 \cdot 3 \%$ of 853 new Ethiopian patients had loss of sole sensation on registration (19\% bilaterally), and that $41.4 \%$ of a group of 1395 old patients had sole sensory loss ( $31 \cdot 3 \%$ bilaterally).

Nerve function changes occur in some patients during treatment or surveillance, often 'silently' in the absence of any nerve pain. Indeed loss of sole sensation, which brings with it lifelong risk of sole wounds, almost always seems to occur silently and thus is not easily identified by field workers. In a group of 475 paucibacillary patients studied ${ }^{5}$ on commencement and completion of their MDT course, $12 \cdot 2 \%$ showed some recovery but also $8 \cdot 2 \%$ suffered decrease in sole sensation whilst on MDT.

Once peripheral nerve impairment is established - that is, no longer amenable to reversal, with or without steroids-disability has a natural tendency to deteriorate; loss of protective sensation tends to result in unnoticed and uncared for wounds, paralysis in stiffness of joints, and dehydrated skin in cracks and callus. This tendency is unaffected by chemotherapy and special, specific measures have to be adopted to prevent it. Smith ${ }^{6}$ in a follow-up of 118 disabled patients out of 175 detected in a survey in a well organized leprosy control programme in India, found that over a 4-year period (from 1979 to 1983$) 71(60 \cdot 1 \%)$ showed no change in WHO disability grading (excluding grade 1$), 19(16 \cdot 1 \%)$ showed improvement and $28(23 \cdot 72 \%)$ had deteriorated. The deterioration was more marked in the borderline lepromatous group, though all classification groups were affected. The mean grade for the 118 patients had increased f rom 1.58 to $1 \cdot 70$. The most striking differences in actual disabilities between the $175(18.8 \%)$ disabled in 1979 and the 152 $(14.6 \%)$ found disabled in 1983 were reductions in numbers with severe absorption from 9 to 1 and with plantar ulcers from 60 to 45 . Dr Smith suggests that this decline is an effect of the disability control programme. There was little change in other disabilities.

In the absence of effective disability control, a patient who completes his course of 
chemotherapy having only 'invisible' sensory loss of the sole, may have lost half of his foot 10 years later. Such deterioration will not appear on present leprosy control records unless these include records of disability in all patients suffering peripheral nerve impairment, whether on or off chemotherapy. Recent reports from Nigeria ${ }^{7}$ and $\mathrm{China}^{8}$ evince concern over the significant numbers of patients (on and off chemotherapy) observed suffering severe deformities and handicaps. Thus the size and severity of the problem which disability and handicap pose to many present-day leprosy patients continues to give cause for concern, and will continue to do so for many years to come.

The purpose of this paper is to discuss ways in which the effectiveness of activities to control (prevent or limit) disability within a leprosy control programme can be improved. Much that is already known about action that can prevent disability is not being consistently applied. Thus it appears that improved management may be the key to improved efficiency and effectiveness. This paper does not attempt to deal with the valuable role of hospitals in the surgical and social rehabilitation of those already disabled.

\section{Improving management of disability control activities}

The WHO Expert Committee ${ }^{1}$ recommends six specific managerial steps for the practical implementation of disability prevention and management at peripheral level.

The first recommendation states that 'the team leader, normally a physician, accepts responsibility for prevention of primary and secondary impairments and disability as part of his or her responsibility for patient care.' This is important. The team leader of a leprosy control programme needs to coordinate activities to control the bacilli with activities to control disability. All team leaders will be concerned over the problems that disability brings to their patients, and most arrange for health education talks to be given at treatment points on the subject of self-care. However if the effectiveness of activities to control disability is to be maximized, the team leader needs also to manage, supervise and evaluate such action. For example he needs to ask if existing resources of time and materials are targeted towards well thought out priorities, and are being used as productively as possible. He will ask whether community or rehabilitation workers outside the vertical leprosy programme could give more support to leprosy patients. When initiating a disability control programme, the team leader's first step may be to ask a physiotherapist or clinician having management skills to study disability problems, to measure the effect of present activities on the incidence of new disability, and to explore new possibilities for action and report back to him.

The second recommendation is that 'specific, limited, measurable objectives are set for preventing and limiting disability, and activity plans based on these objectives are formulated.'

The overall objective of disability control is:

\section{THAT PATIENTS HAVE NO DISABILITY OTHER THAN THAT WHICH WAS GENUINELY IRREVERSIBLE AT REGISTRATION}

Thus if a new patient has no disability at diagnosis, the objective will be to prevent any from occurring. If a new patient already has disability on diagnosis, the objectives will be to prevent any worsening of that disability and to encourage recovery where possible. The overall objective can be subdivided into a number of specific, limited action objectives as shown on Figure 1. Staff need to recheck regularly (monthly if possible) for loss of sensation and strength not only in patients who are on treatment, but also during the period of surveillance. Activities to minimize risks of secondary skin cracks, joint stiffness, wound occurrence and wound neglect, need to be lifelong in patients with irreversible peripheral nerve damage. Therefore, when planning to control disability it is necessary to include all patients suffering peripheral nerve damage, whether or not they are on chemotherapy.

It will probably be necessary to implement and evaluate action to control disability in planned stages such as are indicated in the flow chart shown in Figure 2. 




* "See fourth recommendation

Figure 1.

The third recommendation is that 'impairment and disability records are included in the clinical recording system'. The design of disability records is extremely important. Through them staff can identify:

(i) existing impairments and disabilities to which attention needs to be given;

(ii) improvements which indicate success in action to date and call for celebration; and

(iii) changes for the worse which signify failure to control disability and which indicate a need for prompt action.

It is the last-named information (iii) which is vital for programme evaluation.

The above information is required on the individual patient disability record to enable the clinician in charge of patient care to monitor progress in disability control. It is also needed for the team leader's regional or national statistics, to guide him as he plans for and evaluates action to control disability.

\section{The Individual Patient Disability Record (see Figure 3).}

Information required. The individual patient record should include the following information regarding eyes, hands and feet, together with keys to all tests and signs used:

- Serial sensation and strength records through which changes in nerve function can be monitored, plus a note as to the duration of any change.

Sensation maps need to show the area of sensory loss. Finger and toe drawings should be printed large enough to enable sensation and wounds to be clearly marked. Strength records need to indicate the movement tested and the degree of strength loss. These records can be used both to identify patients losing nerve function and needing neuritis chemotherapy, and to monitor and evaluate the effect of such treatment. 
Stage $1^{*}$ Study disability problems, available resources and obstacles that might impede activities to control disability

Stage $2^{*}$ Select specific, limited, measurable action objectives

Stage $3^{*}$ Make an implementation and evaluation plan

$\downarrow$

Stage 4 Train staff in needed skills and implement the plan

$\downarrow$

Stage 5 Monitor and evaluate the effectiveness and efficiency of the programme at regular intervals $\downarrow$

Stage 6 Modify the plan if and as indicated by stage 5 findings.

Select added objectives if and when resources allow

* See further notes below

Figure 2.

* Stage 1 includes gathering of inf ormation regarding disabilities, identifying important disability problems, and reviewing obstacles that may impede activities to control them. Information regarding numbers of patients with existing disabilities may be found in existing programme reports where the WHO disability grading has been used. More complete information may be gathered from disability records in existing Individual Patient Forms, or by conducting a disability survey in representative areas using the forms shown in Figures 3 and 4 as described below. Information can be obtained informally from patients and staff in regard to the impact of various types of disability on patients' lives, their beliefs as to their cause and 'cure' and any practical problems already encountered in implementing self-care. The data will indicate which are the more serious and widespread problems which need to be tackled first. The next step is to consider possible ways of dealing with these important problems. What resources are available, and what obstacles might hinder proposed action? Can the theoretical solutions be implemented in the given situation?

Stage 2. On the basis of the inf ormation collected in stage 1, action objectives can be selected. These should be feasible, observable and measureable. ${ }^{9}$

Stage 3. When making a plan to implement the selected objectives, it is necessary to outline the activities in detail. For example:

Which people will carry out what activities, and when? What skills do they need to acquire; who will teach them these skills? Where and when?

What materials will be needed, for example shoe materials, teaching pamphlets, record forms?

What funds are needed for the above activities, from where will these be obtained, by whom and when?

When, how and by whom will progress towards selected objectives be monitored and evaluated?

The sensory maps are also of value to staff training patients in wound avoidance, to remind them which particular areas are insensitive and thus at risk of injury and which areas are sensitive and thus 'safe'. Dropped feet, clawed digits and weak muscles need to be exercised.

- Secondary wounds, cracks and bone loss.

Wound sites, sizes, recurrence history and probable causes should be recorded, so that the feasibility of preventing recurrence can be assessed and the pattern of wound healing and recurrence monitored.

The level of bone shortening should be mapped so that any increase in shortening over the years can be monitored. In some situations wound recurrence may be unavoidable. If they are not to be continually disappointed patients and staff need to make sure that they have long term plans and expectations that are realistic. Open cracks should also be mapped and are an indicator of neglect of skin care. Although it is desirable to monitor changes in finger stiffness through finger angle drawings where possible, this is not feasible in most field programmes.

Methods of testing and recording. Basic methods are described in 'Preventing Disability in Leprosy Patients'. ${ }^{10}$ Supervisory and teaching staff should seek to achieve reproducible test results 
DISABILITY RECORD

PATIENT'S NAME Edet Eket. 5031

CLASSIFICATION BT

\begin{tabular}{|c|c|c|c|c|c|c|c|c|c|c|c|c|c|c|}
\hline \multicolumn{7}{|c|}{ RIGHT SIDE } & \begin{tabular}{|c|} 
STRENGTH \\
SWP $=$ Strong $/$ Weak/Paralysed
\end{tabular} & \multicolumn{7}{|c|}{ LEFT SIDE } \\
\hline & & & & & & & DATE & $2 / 12 / 88$ & $3 / 1 / 89$ & & & & & \\
\hline $\mathrm{mm}$ & $\mathrm{mm}$ & $\mathrm{mm}$ & $\mathrm{mm}$ & $\mathrm{mm}$ & $\mathrm{mm}$ & $\mathrm{mm}$ & $\begin{array}{l}\text { Light closure lid } \\
\text { gap in mm }\end{array}$ & $\begin{array}{c}0 \\
\mathrm{~mm}\end{array}$ & $\begin{array}{c}0 \\
\mathrm{~mm}\end{array}$ & $\mathrm{~mm}$ & $\mathrm{~mm}$ & $\mathrm{~mm}$ & $\mathrm{~mm}$ & $\mathrm{~mm}$ \\
\hline 150 & & Yes/No & Yes/ No & Yes/No & Yes/ $/ \mathrm{No}$ & Yes/ $/ \mathrm{No}$ & Blink Normal & res/ No & (res)/No & Yes/ No & Yes/ $/ \mathrm{Na}$ & Yes/ $/ \mathrm{Na}$ & Yes/ $/ \mathrm{Na}$ & Yes/No \\
\hline & & & & & & & Little finger in & $P$ & $P$ & & & & & \\
\hline & & & & & & & Thumb up (palm upwards) & s & $S$ & & & & & \\
\hline & & & & & & & Wrist up & S & $\mathrm{s}$ & & & & & \\
\hline & & & & & & & Foot up & 5 & S & & & & & \\
\hline & & & & & & & ASSESSOR & Jw & JW & & & & & \\
\hline
\end{tabular}

SOLES
LETE/ASSESSOR If answering "yes", detail below

Figure 3. An example of a disability section of an Individual Patient Record

Note: More detailed strength key:

$\mathrm{SRMP}=$ Strong/Resistance reduced/Movement reduced/Paralysed 
through caref ul training of staff and regular quality control checks. Periodically, for example, they should ask several staff members to each make a record on the same patient and then to compare results, with retests where findings differ.

Use. The baseline record is of great importance as it forms the basis for immediate action plans and for all later comparison. Thus it should be completed with the utmost care. New records should always be compared with previous records in order to check forchange. Too of ten stafff ail to make this comparison and thus lose the opportunity to take appropriate action when new problems arise ${ }^{11}$ and to rejoice with the patient when improvements are achieved. Suspected changes should be confirmed by visual evidence or history.

\section{The Team Leader's Regional or National Yearly Report}

In order that he can give appropriate direction to the disability control programme, the team leader should aim to determine each year:

Numbers of patients affected by primary effects of nerve dysfunction (sensory and strength loss) and by secondary problems (wounds, cracks, bone loss).

Changes in type and in extent of disability occurring within the past year.

An example of a form on which such information is summarized is shown in Figure 4. Sensation, strength, vision, wounds plus open cracks and bone loss have all been scored. Changes in score since the previous year are shown in the final column. Sensory loss has been scored by counting 1 for each dot site on the hand or sole maps at which sensation (or bone) has been lost. Strength test results have been scored on the basis of 2 for paralysis, 1 for weakness and 0 for normal strength. Wounds plus open cracks have been counted. Bone loss has been scored by area.

Very significant changes can occur in the extent of disability without any change occurring in the WHO disability grade, and thus the grading is not appropriate for evaluation of the disability control programme. ${ }^{12}$ The grading can however be used to gain a rough idea of the extent of disability in a group of patients, and as an indicator by which new case finding can be monitored from year to year.

The fourth recommendation is that 'arrangements are made for the provision of protective footwear and other aids.'

\section{Protective footwear}

Requirements of footwear for insensitive feet are that it should be as far as possible protective, accessible to field patients, locally repairable and acceptable to the patient in cost, function and style. Priority should be given to footwear for younger outpatients in whom the first ulcers can be prevented.

The team leader needs first to estimate numbers of patients with sole sensory loss, who thus need ongoing access to a source of protective footwear. In the absence of sole sensation records he may initially plan for footwear for $20 \%$ of accumulated patients. He then needs to acquire information regarding protective footwear currently available:

What sources of suitable, protective footwear currently exist?

How many pairs of protective footwear were made in programme workshops during the past year by each shoemaker, and in total? A full-time shoemaker, without any machinery to assist him, should be able to make 300 new pairs and also to repair 300 pairs in a year. Where production is below this target, this may be due to lack of orders for footwear, to lack of materials or to slow work habits.

How long does the average pair of sandals last? What are the weak points at which repairs are commonly needed? Can weak areas be strengthened? 
SIMPLE DISABILITY REVIEW

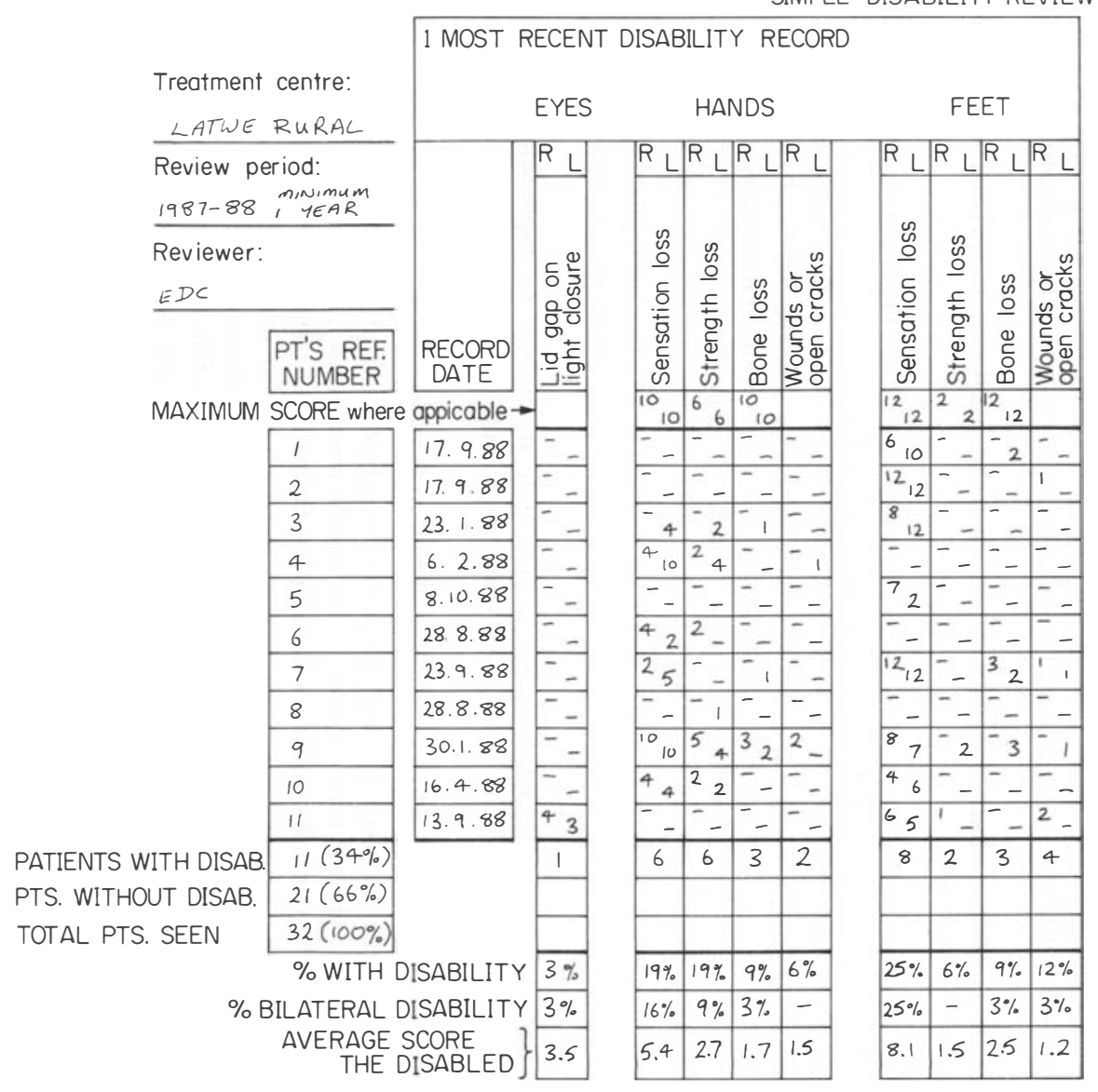




Are patients making regular use of the footwear? If not, why not? Are they repairing the footwear saf ely?

On the basis of this information the team leader can plan to improve footwear design and supply. Programme shoe workshops may be asked to maintain a stock of standard-sized, protective footwear having adjustable straps. This can be distributed through programme supervisors to field patients with insensitive soles, but normally shaped feet. However, it is important that the team leader adopts a flexible approach when seeking possible sources of protective footwear and of footwear funding. It may well be that soft-insoled footwear which will afford protection can be bought in local shops or made or modified by local shoe-makers. ${ }^{13}$ The cost of keeping all patients with sole sensory loss supplied with free footwear is likely to be prohibitive. However, many working outpatients are accustomed to buying their own market footwear, and thus should be able to contribute to the cost of protective footwear.

\section{Other protective aids}

Staff should learn through experience what other aids help patients to avoid injuries. The most generally usef ul are spectacles for eyes with inefficient blink, and thick, simply sewn towelling bags that can protect insensitive hands from cooking burns much more effectively than the pieces of cloth so of ten recommended to patients lifting hot pots. Field staff should try to carry two or three samples of aids with them for distribution as indicated, or to show to patients able to make or obtain their own.

Thefifth recommendation is that 'patients are instructed in self-care and in behaviour designed to prevent further disability'.

All patients on chemotherapy or surveillance need to understand the need to report immediately any change in sensation or strength and any nerve discomfort.

Patients with peripheral nerve dysfunction affecting eyes, hands or feet, need to learn how they can gain access to replacement protective devices, and what lifelong habits of care they need to adopt in order to prevent secondary complications: $:^{10}$ a daily routine of inspection, skin or eye care, and exercise; an all-day alertness to, and avoidance of, possible sources of injury; and early detection and effective care of wounds.

In particular patients with sole sensory loss need to learn from experience of sole injury just how much walking causes recurrence of their ulcers, so that they can keep their walking within safe limits if at all possible.

The sixth Committee recommendation is that 'staff are trained to implement the disability prevention programme, to teach patients self-care and to monitor and support the practice of selfcare by patients.'

Three points regarding training methods deserve special emphasis:

- The need initially to make sure that the patient really understands his self-care, and that advice given is practical. Having once demonstrated needed routines to a patient and advised on their importance, it is best on subsequent occasions to ask the patient to demonstrate and discuss what he already does in the way of self-care rather than to repeat the advice. By observing as the patient demonstrates care, staff will be able to identify areas in which more teaching is indicated. For example the lady with cooking burns may be folding the cloth too thinly as she lifts hot pots, or may have failed to notice that her fingers are off the edge of the cloth. By listening carefully as the patient describes the practical problems he is encountering in following advice given, or his reasons for disbelieving this advice, staff will be better able to understand his problems, and to offer meaningful, practical support and ideas. For example the patient, whose wife carries the waterf or $5 \mathrm{~km}$ to the house, and who objects to his using it all forf oot soaking, may learneither to soak in a water source 
that he passes during his daily activities or to use only a cupful of water poured into a tilted bowl when cleaning his wound or soaking his callused heel skin.

- The need for staff to encourage patients to persevere in the self-care that they have learnt, and to demonstrate their concern and care by action rather than through words. Advice alone is not enough. Thus, for example, if field and ward staff see patients with neglected skin, they will enable the patient to carry out immediate skin care, and then express pleasure on seeing the improvements that result.

- The essential need for middle-level supervisors to maintain interest in disability control activities and standards.

Leprosy control consists of disability control as well as the control of bacilli. By improving management aspects of disability control it should be possible to increase its effectiveness, and thus to minimize the handicaps that can so seriously affect a patient's quality of life.

The Leprosy Mission International

JEAN M WATSON

80 Windmill Road

Brentford

Middlesex TW8 OQH

England

\section{Acknowledgments}

I am grateful to Dr H W Wheate, Dr G Boerrigter and Miss P J Neville for giving suggestions and critical comments on the manuscript.

\section{References}

1 WHO Expert Committee on Leprosy, sixth Report. WHO Technical Report Series. No. 768. WHO, Geneva, 1988.

${ }^{2}$ Boerrigter G, Ponninghaus JM. A new concept of staging paucibacillary leprosy and its application to the analysis of post-treatment results of a MDT study in Malawi. 13th Int. Lepr Congress 1988; FP 014.

${ }^{3}$ Leprosy Control in Malawi. The 1987 Annual Report of LEPRA.

41987 Annual Report of the Tanzania National TB/Leprosy Programme.

${ }^{5}$ Becx-Bleumink M. Personal communication (1989).

${ }^{6}$ Smith WCS. Evaluation of a leprosy control programme in India. MD Thesis University of Aberdeen. 1986.

7 Waaldijk K. The actual leprosy situation within Katsina State, Nigeria. Lepr Rev, 1988; 59: 355.

${ }^{8}$ Zheng Tisheng et al. Disability Survey in 1480 cases of leprosy. 13th Int. Lepr. Congress 1988, FP 061.

9 McMahon R, Barton E, Piot M. On Being in Charge, WHO Geneva 1986.

10 Watson JM. Preventing Disability in Leprosy Patients. Published 1986, The Leprosy Mission. Reprinted 1988.

${ }^{11}$ Hamilton J. Deformity prevention in the field: a systematic approach. Lepr Rev, 1983; 54: 229-37.

12 Watson JM. WHO Disability Grading. Lepr Rev, 1985; 56: 172-5.

13 Watson JM. Footwear for Leprosy Out-patients. To be published by The Leprosy Mission. 